\title{
A LETTER FROM THE UNITED STATES OF AMERICA DEALING WITH VENEREAL DISEASES
}

\section{II}

THE vast change that has taken place in recent years in our concept of chancroid as a definite clinical entity in the classic triad of venereal diseases, is emphasised in an interesting report by Dr. R. P. Parsons, Lieut.Commander, Med. Corps, United States Navy, in charge of the urological and venereal service at the Naval Hospital at San Diego, California.

Discussing the subject "Syphilis in the Navy," he stresses the importance of a positive diagnosis of the primary lesion before treatment is instituted : and in this connection he states that many, if not all, of the so-called "chancroids" are really not chancroids at all, but primary syphilitic lesions. He believes that " real chancroid is such a rare thing in this country that we can consider it practically non-existent." About 90 per cent. of all genital sores, he says, turn out to be syphilitic, the remaining ro per cent. being made up chiefly of scabies, herpes, furuncles and abrasions, and he estimates that of the 2,722 " chancroids" admitted during I932, at least 2,600 were really syphilis. Of several hundred cases of genital sores per year on his service, and so far this year, only one case was dismissed as non-syphilitic after intensive study for three months. This study consisted of almost daily dark-field tests, weekly Kahn tests, and weekly physical examinations.

He declares it is almost a daily occurrence to admit a case of some old syphilitic lesion-cardio-vascular disease, neuro-syphilis, old skin ulcers, bone syphilis, etc., and find in the hospital record a notation of chancroid dated many months or years previously. The rule he has established on his service is to continue weekly Kahn tests for six months in every case of genital sore, unless diagnosed syphilis before that time. Another rule is that no patient is allowed to leave the hospital with the 


\section{LETTER FROM UNITED STATES OF AMERICA}

diagnosis of chancroid. As above stated, only one exception to this rule has been made thus far this year.

Fully one-half of the patients admitted to the syphilitic department arrive with the diagnosis of chancroid, and of these about 95 per cent. are changed to syphilis within the first week at the hospital, and fully 99 per cent. get labelled "syphilis" before they leave the hospital. The conclusions are based on dark-field and Kahn tests in the early cases and on Kahn tests plus clinical findings in the late cases.

From these observations coming from so authoritative a source as Commander Parsons and from others who have made somewhat similar observations, it is clear that a drastic revision of our classic concept of chancroid is inevitable. In the light of these recent researches we must now define chancroid as merely one of many varieties of genital ulcers, its specific etiologic factor being the bacillus of Ducrey, and that no definite diagnosis of chancroid can be made unless and until syphilis has been positively ruled out by the repeated employment of the dark-field and the Wassermann or Kahn test for a period of at least three or four months.

In a symposium on the venereal diseases recently held by the New York Physicians-Yorkville Medical Society, Dr. Leo Spiegel discussed the modern treatment of syphilis. He said by way of introduction, that syphilis is a systemic general disease days before the appearance of the chancre. There is no way of identifying a genital lesion except the dark-field, which reaches its highest efficiency in the first two weeks of the primary lesion, and by the serological blood tests thereafter. In 90 per cent. of cases the diagnosis can be made by dark-field in the first two weeks. A negative dark-field, even if repeatedly so, is not sufficient to eliminate syphilis ; by the sixth or eighth week the Wassermann reaction is positive in 80 per cent. or more.

In early syphilis one may treat the disease; in late syphilis one must treat the patient. Excision of the chancre for the abortion of syphilis has been abandoned as useless. For his own good, while under treatment, the patient should not be informed of the sero-reaction becoming negative, as most patients then discontinue 


\section{BRITISH JOURNAL OF VENEREAL DISEASES}

treatment, believing they are cured. The slogan of the best modern practice is " treat by schedule and not by the Wassermann test."

Among the arsenicals the choice lies between arsphenamin, neo-arsphenamin, and silver arsphenamin. The efficiency of arsphenamin is I5o per cent. that of the Neo-, and is the choice of most of the large American clinics. He prefers silver arsphenamin personally in early syphilis, given in courses of 12 injections. The initial dose is $O . \mathrm{Igm}$. in Io c.c. of water, and subsequent doses are no higher than $0.2 \mathrm{gm}$. Bismuth is given simultaneously. It should never be given in more than onehalf the therapeutic dose at the first injection. The toxicity of silver arsphenamin is less than that of arsphenamin or neo-arsphenamin. It should not be given in greater total than $8 \mathrm{gm}$. for fear of producing argyrosis.

The popularity of neo-arsphenamin is due to the ease of administration. The maximum effective dose is 0.6 gm. and not 0.9 as heretofore believed. Bismuth can be given simultaneously in two series of 20 injections each. Bismuth never should be given intravenously. Relapses are more common with arsphenamin and mercury combined than with arsphenamin and bismuth combined.

Reactions are generally due to excessive speed of injection. A small needle, 23 gauge, should be used, and the injection made slowly. The " ether" or "garlic" odour which occurs with neo-arsphenamin, never occurs with silver arsphenamin. It is caused by the ether used in its manufacture. Chewing gum or a mint and breathing through the mouth decreases the odour. The patient need not be starved for three or four hours before the injections; the speaker allows some milk chocolate or ice-cream soda one half-hour before injection. Either of these taken immediately after an injection helps to prevent reactions. Nitritoid crises are rarely fatal ; they usually pass off in half-an-hour; they rarely follow the first injection. They are more common after neoarsphenamin than after arsphenamin and rarely after silver arsphenamin. They are due to too rapid injection.

The question of cure must be considered from the clinical, biological and serological standpoints. Early syphilis is easily curable in the biologic sense; late 


\section{LETTER FROM UNITED STATES OF AMERICA}

syphilis in the clinical sense. In the light of our present knowledge of the disease, no series of serologic tests on the blood or spinal fluid can carry weight with respect to " cure," for it is well known that progress of the infection can take place even when these tests are persistently negative, as in cardio-vascular and neuro-syphilis. A serologic cure is therefore by no means equivalent to a clinical cure. The best we can say is that when the blood and spinal fluid are persistently negative and the patient has received adequate "standard" treatment, he may be declared cured. The only proof of cure is time and observation. Never discharge a patient as "cured." Keep him under observation, preferably throughout life. This is the only assurance that can be offered against insidious unrecognised progression and relapse. During the probationary two years following the cessation of "standard" treatment, observation and serologic tests are desirable three or four times a year. After this period yearly physical examinations and blood tests without repetition of the spinal fluid test, if negative twice previously, is in order. In the fifth year and thereafter, $\mathrm{X}$-ray and cardiologic study of the heart and aorta is desirable. Only by such supervision can the greatest security be assured for the patient.

It may be said, by way of comment, that the treatment thus outlined is fairly representative of the best American opinion, with the exception, perhaps, of the speaker's preference for silver arsphenamin, which is used very little by comparison with neo-arsphenamin, by American physicians generally.

J. A. Goldberg, Ph.D., Secretary, Social Hygiene Committee of the N.Y. Tuberculosis and Health Association, spoke on the prevention of venereal disease, from the angle of a public health worker. He stressed the importance of education as a preventive, particularly in high schools and colleges, by properly trained teachers with the essential personality factors. He told of a woman's college in New York where an inadequate personality blocks the path of proper and positive instruction. As some of the graduates have put it: "What does that prim old maid with a high collar and necktie know about sex?-and yet she is supposed to teach young women all about it." In some colleges, he said, courses in biology and hygiene omit all material 


\section{BRITISH JOURNAL OF VENEREAL DISEASES}

relating to the venereal diseases. Another, more practical approach, is needed.

A recent survey showed that very little was being done to educate nurses in this field, and the same is true, to a lesser degree, as regards medical schools. The physician, after all, is the important factor in the prevention and control of the venereal diseases. He thought physicians were not fully alive to the widespread incidence of syphilis and gonorrhœa. As an example of this incidence he told of a study of prenatal syphilis covering twenty-eight New York institutions over a period of five years, which showed a range of less than I per cent. of syphilis in an institution catering almost exclusively for Jewish women, to I5 to I9 per cent. in various municipal hospitals.

He quoted Dr. Joseph Earle Moore, of Johns Hopkins, to the effect that after fifteen years of experience in syphilology, he has reached the rather disquieting conclusion that we are not progressing in the control of syphilis, but going backward, and that the disease is increasing, not decreasing.

The speaker asked how much good is being done in the venereal disease clinics with their inevitable crowding, lack of privacy and inadequate trained personnel. He advocated payment of clinic physicians, especially where the case loads were heavy and the case records necessarily ioorly kept. He pointed out that indifferent clinical work, whether in private office or in public institutions nullifies much that may be done in the field of prevention. $\mathrm{He}$ concluded by saying that those engaged in public health activities concerned with the prevention and treatment of the venereal diseases, look to the well-trained and public-health minded physicians as the major bulwark in the campaign which must be constantly carried on against syphilis and gonorrhœa in their initial stages, as well as in the subsequent complications that so often arise.

Opening the discussion of these papers, Dr. Walter Clarke, of the American Social Hygiene Association, said that it was quite appropriate to discuss together the treatment of early syphilis and the prevention of venereal diseases, for by modern treatment syphilis and gonorrhœa can be rendered non-infectious. This is especially true of syphilis. Even a few doses of arsphenamin render syphilis temporarily non-infectious, and more 


\section{LETTER FROM UNITED STATES OF AMERICA}

thorough treatment prevents infectious relapses in a large proportion of cases. His observations and studies in both the United States and abroad, and his own clinical experience, lead him to agree with Dr. Spiegel regarding the advisability of continuous rather than other methods. of treating early syphilis. Among other points on which there is fairly general agreement are the following: The advisability of smaller dosage of the arsenicals than were common a few years ago ; emphasis on the arsenicals. in the treatment of early syphilis, and on the heavy metals in the treatment of late syphilis; the necessity for a thorough medical examination of every case of syphilis before instituting treatment, and the differentiation of treatment according to the medical conditions; and finally; the limitations of the serological reports as guides to the duration of treatment.

Referring to Dr. Goldberg's mention of some of the shortcomings of clinics for the treatment of syphilis and gonorrhœa, he would stress the need to prepare general practitioners more adequately to recognise syphilis in their patients. Missed cases and errors in treatment are so numerous that one is led to look for the reason. Studies of this problem indicate that on the whole and with few exceptions, instruction regarding syphilis given in medical schools in the United States is fairly satisfactory, but that hospitals do not, in a large proportion of instances, give their " interns" practical experience in the diagnosis and treatment of this prevalent and serious. disease. Students in medical schools learn the theoretical aspects of syphilis fairly well, but fail to get the practical clinical experience in the course of their internship. Many go out into general practice with insufficient clinical knowledge of the disease and its diagnosis and treatment.

When this weakness in our scheme of medical education is corrected, we shall have general practitioners more adequately prepared to cope with syphilis in their patients, and this will be a long step toward the medical and public health solution of the problems which surround this disease. 